\title{
Analisis Karakteristik Input-Output dan Optimasi Biaya Pembangkitan Menggunakan Metode Quadratic Least Square Regression dan Metode Dynamic Genetic Algorithm
}

\author{
(Analysis of Input-Output Characteristic and Generation Cost Optimization Using Quadratic Least \\ Square Regression Method and Dynamic Genetic Algorithm Method)
}

\author{
Rina Anggraeni ${ }^{1}$, Dedy Kurnia Setiawan ${ }^{2}$, Triwahju Hardianto ${ }^{3}$ \\ Jurusan Teknik Elektro, Fakultas Teknik, Universitas Jember (UNEJ) \\ Jln. Kalimantan 37, Jember 68121 \\ E-mail: rinaoliphanggraeni@gmail.com¹,dedy.kurnia@unej.ac.id², triwahju@gmail.com ${ }^{3}$
}

\begin{abstract}
Abstrak
Optimalisasi produksi listrik, khususnya pada pembangkit termal membutuhkan analisis karakteristik input-output dan pembebanan yang tepat agar beroperasi dengan baik. Karakteristik input-output akan mengawasi pergeseran yang terlihat dari kurva dan mendeteksi perlu adanya maintenance atau tidak pada sebuah pembangkit. Karakteristik input-output dapat dihitung dengan metode quadratic least square regression. Sedangkan pembebanan yang tepat, membuat produksi listrik sesuai maksimal beban yang diinginkan dengan biaya paling murah. Perhitungan pembebanan dilakukan dengan metode dynamic genetic algorithm. Metode ini diaplikasikan pada data PT. PJB UP Gresik bulan Juli 2015 didapatkan total biaya bahan bakar yang dihemat sebesar 3.162,9147 KNM3 dan biaya bahan bakar sebesar \$22.773 dibandingkan PJB.
\end{abstract}

Kata Kunci: dynamic genetic algorithm, economic dispatch, karakteristik input-output, quadratic least square regression.

\section{Abstract}

For optimization of electricity production, especially in the thermal power plant required analysis of input-output characteristics and operated load properly. Input-output characteristics will oversee the curve and detected the plant need for maintenance or not. Input-output characteristics can be calculated by least squares quadratic regression method. operated load properly, making electricity production corresponding maximum desired load with lowest cost. Loadi calculations performed by dynamic genetic algorithm method. This method is applied to data from PT. PJB UP Gresik in July 2015 has saving 3.162,9147 KNM³ fuel consumption and \$22.773 fuel costs compared PJB.

Keywords: dynamic genetic algorithm, economic dispatch, karakteristik input-output, quadratic least square regression.

\section{PENDAHULUAN}

Seiring pemakaian pembangkit termal secara terus menerus dalam pembangkitan energi listrik, mengakibatkan performa pembangkit mengalami perubahan. Untuk mengetahui perubahan performa suatu pembangkit ini, maka digunakanlah kurva karakteristik input-output.

Kurva input- output akan menunjukkan hubungan antara bahan bakar dan daya yang dihasilkan oleh pembangkit. Ada beberapa cara untuk menghitung karakteristik input-output, seperti dengan metode Lagrange dan metode Gauss Jordan. Penelitian sebelumnya menjelaskan bahwa metode Lagrange, memiliki kelemahan yaitu pada ketelitan yang kurang presisi. Sedangkan metode Gaus Jordan memiliki kelemahan hanya dapat diaplikasikan pada data-data tertentu, karena pada intinya metode ini mengharuskan data djadikan matrik eselon yang tereduksi yang tidak bisa diaplikasikan pada semua data.

Dari permasalahan ini metode quadratic least square regression dapat diaplikasikan untuk menyempurnakan dua metode sebelumnya, karena metode ini dapat memberikan hasil yang lebih presisi dan dengan operasi regresi sederhana sehingga dapat diaplikasikan pada semua data. Metode least square menyatakan bahwa "jumlah kuadrat selisih dari nilai sebenarnya dengan nilai yang terhitung, dikalikan jumlah pengukuran adalah minimum”. Metode least square merupakan metode estimasi parameter system yang meminimumkan fungsi kriteria jumlah kuadrat kesalahan prediksi [1]. Hasil dari perhitungan ini, akan menghasilkan persamaan untuk dibuat kurva yang digunakan untuk melihat performa dari sebuah pembangkit dan juga kurva ini dapat digunakan sebagai parameter untuk menentukan perbaikan/maintenance pada pembangkit, baik perbaikan biasa maupun overhaul.

Selain performa pembangkit yang harus dikontrol setiap saat, pemilihan pengoperasian pembangkit juga memerlukan pengaturan. Hal ini dilakukan agar mendapatkan daya yang besar dengan biaya pembangkitan paling minimal. Pengaturan pemilihan pegoperasian pembangkit ini dapat dilakukan menggunakan economic dispatch. Banyak metode yang dapat digunakan untuk menyelesaikan masalah economic dispatch ini, salah satunya dengan menggunakan metode genetic algorithm. Akan tetapi, pada paper berjudul Evolution of Appropiate Crossover and Mutation Operator in a Genetic Process disebutkan bahwa metode ini hanya bisa melakukan satu kali persilangan dan mutasi untuk mendapatkan generasi baru [2]. Sehingga hasil yang didapatkan menjadi kurang detail. Kelemahan pada genetic algorithm ini disempurnakan dengan solusi menambahkan perhitungan 
kecocokan jumlah rasio setiap kali melakukan persilangan dan mutasi ntuk mendapatkan hasil yang lebih detail dan presisi. Metode penyempurnaan dari genetic algorithm dengan lebih dari satu kali mutasi ini disebut dynamic genetic algorithm. Dengan menggunakan metode dynamic genetic algorithm ini diharapkan dapat memberikan solusi yang paling baik untuk penyelesaian economic dispatch.

\section{METODE PENELITIAN}

Proses penelitian tentang analisis karakteristik inputoutput dan optimasi biaya pembangkitan menggunakan metode dynamic genetic algorithm dilaksanakan di PT. PLN PJB UP Gresik. Kapasitas daya yang dimiliki PLTGU Gresik $\pm i \quad 600 \mathrm{MW}$ yang terdiri dari 4 unit dengan rincian Unit 1 sebesar $100 \mathrm{MW}$, Unit 2 sebesar $100 \mathrm{MW}$, Unit 3 sebesar $200 \mathrm{MW}$ dan Unit 4 sebesar $200 \mathrm{MW}$ (PT. PLN PJB UP Gresik, 2012). Dalam melakukan penelitian ini beberapa langkah harus dilakukan secara runtut sebagai berikut :

1. Melakukan pengambilan data terbaru input-output pada pembangkit.

2. Membuat persamaan matematis menggunakan metode quadratic least square regression.

3. Membuat kurva input-output dari hasil metode quadratic least square regression.

4. Menganalisis perubahan kurva karakteristik input output dibandingkan dengan kurva ideal dengan menggunakan Graphical User Interface (GUI) Matlab.

5. Hasil karakteristik input-output, data pembangkit dan pembebanan dijadikan masukan proses optimasi biaya pembangkitan menggunakan metode dynamic genetic algorithm.

6. Bandingkan economic dispatch hasil metode dynamic genetic algoritm dengan data pembangkitan dari pembangkit.

Langkah-langkah ini diperjelas dengan flowchart diagram alir pada Gambar 1.

Tabel 1. Hubungan Daya dan Bahan Bakar PJB

\begin{tabular}{cccccccc}
\hline \multicolumn{2}{c}{ PLTU 1 } & \multicolumn{2}{c}{ PLTU 2 } & \multicolumn{2}{c}{ PLTU 3 } & \multicolumn{2}{c}{ PLTU 4 } \\
\hline $\begin{array}{c}\text { Day } \\
\text { a }\end{array}$ & $\begin{array}{c}\text { Gas } \\
\text { Flow }\end{array}$ & $\begin{array}{c}\text { Day } \\
\text { a }\end{array}$ & $\begin{array}{c}\text { Gas } \\
\text { Flow }\end{array}$ & Daya & $\begin{array}{l}\text { Gas } \\
\text { Flow }\end{array}$ & Daya & $\begin{array}{c}\text { Flo } \\
\text { w }\end{array}$ \\
\hline 45 & 12,23 & 42 & $\begin{array}{c}12,1 \\
0\end{array}$ & 105 & 22,62 & 80 & $\begin{array}{c}21,2 \\
0\end{array}$ \\
\hline 46 & 12,65 & 44 & $\begin{array}{c}12,2 \\
5\end{array}$ & 106 & 22,79 & 90 & $\begin{array}{c}23,0 \\
0\end{array}$ \\
\hline 61 & 16,21 & 45 & $\begin{array}{c}12,3 \\
2\end{array}$ & 107 & 23,01 & 102 & $\begin{array}{c}24,9 \\
0\end{array}$ \\
\hline 66 & 17,31 & 46 & $\begin{array}{c}12,6 \\
7\end{array}$ & 108 & 23,20 & 107 & $\begin{array}{c}25,2 \\
0\end{array}$ \\
\hline 67 & 17,46 & 65 & $\begin{array}{c}16,6 \\
1\end{array}$ & 134 & 28,05 & 108 & $\begin{array}{c}25,4 \\
0\end{array}$ \\
\hline 78 & 20,33 & 67 & $\begin{array}{c}17,0 \\
9\end{array}$ & 141 & 28,58 & 110 & $\begin{array}{c}26,5 \\
0\end{array}$ \\
\hline 79 & 20,56 & 84 & $\begin{array}{c}20,8 \\
4\end{array}$ & 160 & 32,98 & 160 & $\begin{array}{c}38,0 \\
0\end{array}$ \\
\hline 80 & 21,07 & 85 & $\begin{array}{c}21,6 \\
4\end{array}$ & 169 & 39,08 & 170 & $\begin{array}{c}39,3 \\
3\end{array}$ \\
\hline 81 & 22,41 & & & 170 & 35,68 & 175 & $\begin{array}{c}39,9 \\
0\end{array}$ \\
\hline 84 & 23,34 & & & & & & \\
\hline 85 & 23,89 & & & & & & \\
\hline
\end{tabular}

\section{HASIL PENELITIAN}

PT. PJB UP Gresik memiliki unit pembangkit termal pada PLTU yang masih beroperasi normal saat ini adalah PLTU 1 dengan kapasistas 100 MW, PLTU 2 dengan kapasitas 100 MW, PLTU 3 dengan kapasitas 200 MW dan PLTU 4 dengan kapasitas 200 MW. Masing-masing PLTU memiliki produksi pembebanan yang berbeda-beda dalam sehari. Untuk PLTU 1 dan PLTU 2, produksi paling minimal berkisar $45 \mathrm{MW}$ dan tertinggi $85 \mathrm{MW}$. Sedangkan PLTU 3 dan PLTU 4, produksi paling minimal berkisar 108 MW dan tertinggi 185 MW. Dalam skripsi ini, dibagi menjadi 2 kelompok analisis, yaitu analisis pembangkit periode bahan bakar gas dan analisis periode bahan bakar liquid.

\section{Analisis Pembangkit dengan Bahan Bakar Gas}

Periode bahan bakar gas dimulai dari Januari 2013 hingga tahun 2016 ini. Bahan bakar yang digunakan adalah natural gas yang diambil dari pengeboran langsung tanpa diolah lebih lanjut. Bahan bakar ini memiliki satuan $\mathrm{KNM}^{3}$ dengan harga beli sebesar $\$ 7,2 / \mathrm{KNM}^{3}$.

1. Analisis Karakteristik Input-Output Periode Gas

Analisis karakteristik input-output pada periode gas ini digunakan data sampel pada bulan Mei hingga Juli 2015. Data yang didapatkan dari PT. PJB UP Gresik merupakan data harian, sehingga data tersebut dicuplik dan diambil beberapa data dengan variasi beban. Cuplikan data ditampilkan pada tabel 1.Dari data tabel 1, data tersebut digunakan sebagai masukan metode quadratic least square regression yang dikombinasikan dengan Graphical User Interface (GUI) untuk mendapatkan karakteristik inputoutput. Perhitungan ditunjukkan seperti pada Gambar 2.

Dari perhitungan, didapatkan konstanta pembangkit pada Tabel 2 .

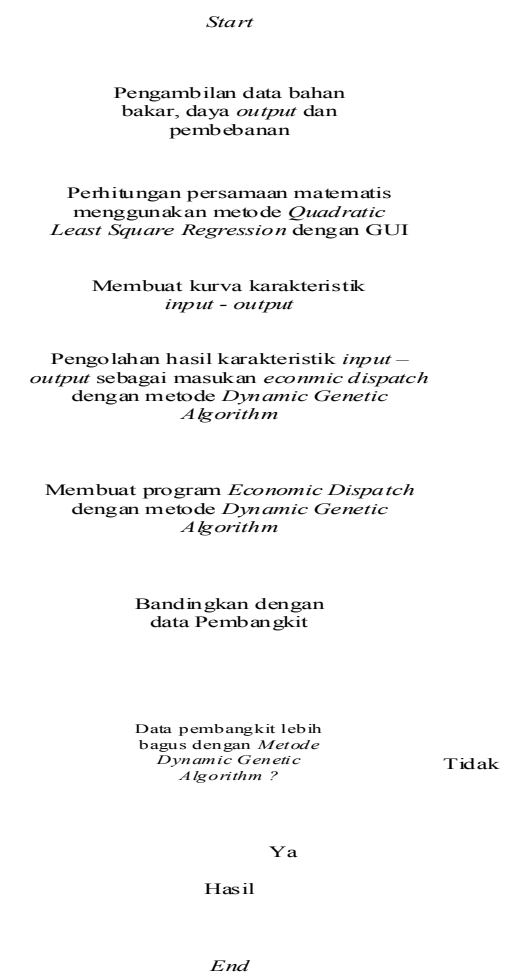

Gambar 1. Diagram Alir Economic Dispatch 
Dari konstanta pembangkit yang didapatkan, maka akan dibentuk kurva karakteristik input-output untuk mengetahui hubungan daya dan bahan bakar pada pembangkit. Kurva ini dapat digunakan sebagai indikator untuk melihat performa dari sebuah pembangkit. Gambar 3 merupakan kurva karakteristik input-output pada PLTU 1. Pada kurva ini terlihat bahwa semakin besar bahan bakar yang digunakan, maka daya yang dihasilkan juga semakin besar atau hubungan daya dan bahan bakar berbanding lurus. Artinya PLTU 1 masih dalam kondisi yang baik, hal ini diperkuat dengan adanya laporan PT. PJB UP Gresik yang menyebutkan bahwa PLTU 1 melakukan overhaul terakhir pada tanggal 30 April 2016 hingga 20 Mei 2016 selama 30 hari.

Gambar 4 merupakan kurva karakteristik input-output PLTU 2. Dilihat dari kurva yang dibentuk, dapat disimpulkan bahwa PLTU 2 masih beroperasi dengan baik. Hal ini diperkuat dengan fakta bahwa PLTU 2 melaksanakan overhaul terakhir pada 16 Mei 2015 sampai 22 Juni 2015 selama 45 hari.

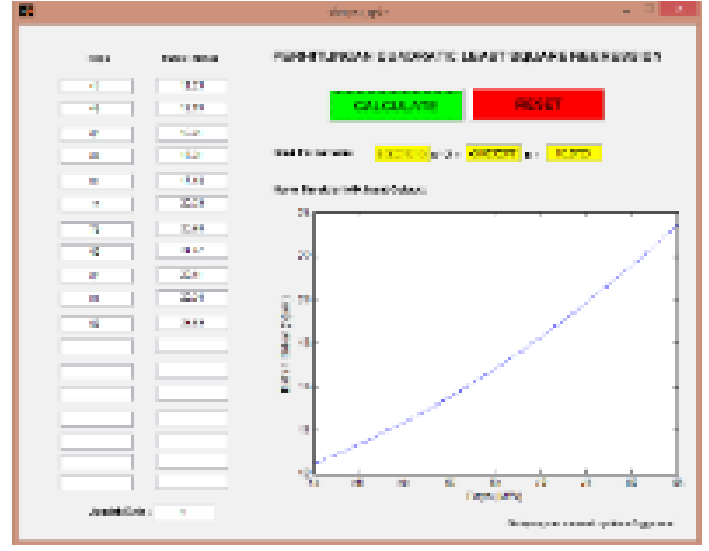

Gambar 2. Perhitungan Karakteristik Input-Output

Tabel 2. Konstanta Pembangkit

\begin{tabular}{cccc}
\hline \multirow{2}{*}{ Unit Pembangkit } & \multicolumn{3}{c}{ Konstanta Pembangkit } \\
\cline { 2 - 4 } & $\mathrm{a}$ & $\mathrm{b}$ & $\mathrm{c}$ \\
\hline PLTU 1 & 0,0028 & $-0,0855$ & 10,6793 \\
\hline PLTU 2 & 0,0016 & 0,0312 & 7,8453 \\
\hline PLTU 3 & 0,0018 & $-0,2645$ & 31,0498 \\
\hline PLTU 4 & 0,0004 & 0,0910 & 10,8872 \\
\hline
\end{tabular}

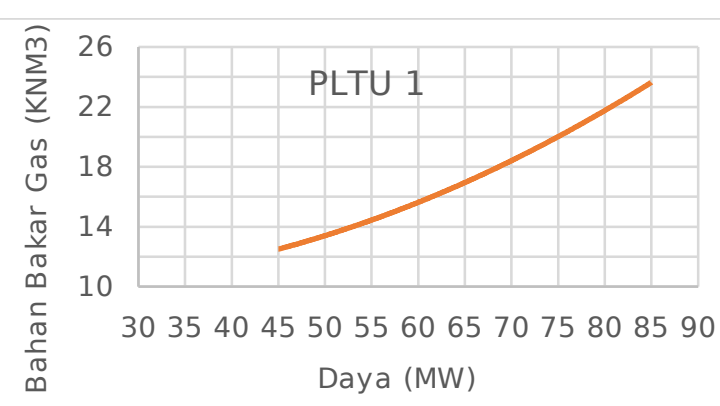

Gambar 3. Kurva Karakteristik Input-Output PLTU 1

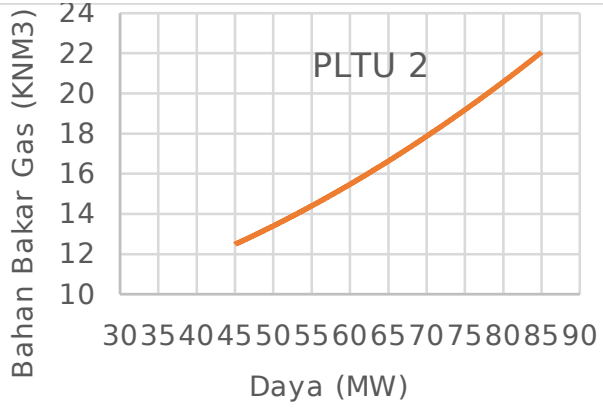

Gambar 4. Kurva Karakteristik Input-Output PLTU 2

Gambar 5 merupakan kurva karakteristik input-output PLTU 3. Sama seperti PLTU 1, pada kurva hubungan daya dan bahan bakar berbanding lurus yang berarti akan dihasilkan daya yang besar dengan kontribusi bahan bakar yang besar pula. Pergeseran yang dialami PLTU 3 juga tidak signifikan dan masih pada batas wajar karena baru saja dilakukan overhaul pada tanggal 22 November 2016 hingga 5 Januari 2016.

Gambar 6 merupakan kurva karakteristik input-output untuk PLTU 4. Sama dengan PLTU 3, PLTU 4 dibebankan beban operasi yang lebih tinggi daripada PLTU 1 dan PLTU 2. Beban minimum yang ditanggung PLTU 4 sebesar 108 MW dengan beban maksimum sebesar 185 MW. PLTU 4 terakhir mengalami overhaul pada tanggal 27 Agustus 2015 hingga 9 Oktober 2015, dan dari kurva yang dibentuk dapat dianalisis bahwa PLTU 4 masih beroperasi dengan baik karena tidak terjadi penyimpangan kurva yang terjadi.

Tabel 3. Pembebanan Unit Pembangkit

\begin{tabular}{|c|c|c|c|c|c|c|c|c|c|}
\hline \multirow{3}{*}{$\begin{array}{l}\text { Ta } \\
\text { ng } \\
\text { gal }\end{array}$} & \multicolumn{4}{|c|}{ Pembebanan PJB } & \multicolumn{4}{|c|}{ Pembebanan DGA } & \multirow{3}{*}{$\begin{array}{l}\mathrm{Be} \\
\text { ban }\end{array}$} \\
\hline & \multicolumn{4}{|c|}{ Unit Pembangkit } & \multicolumn{4}{|c|}{ Unit Pembangkit } & \\
\hline & $\# 1$ & $\# 2$ & $\# 3$ & $\# 4$ & $\# 1$ & $\# 2$ & \#3 & $\# 4$ & \\
\hline 1 & 45 & 45 & $\begin{array}{c}10 \\
8\end{array}$ & 107 & 45 & 45 & 115 & 100 & $\begin{array}{r}30 \\
5\end{array}$ \\
\hline 2 & 45 & 45 & $\begin{array}{c}10 \\
8\end{array}$ & 107 & 45 & 45 & 115 & 100 & $\begin{array}{r}30 \\
5\end{array}$ \\
\hline 3 & 46 & 85 & $\begin{array}{c}10 \\
8\end{array}$ & 107 & $\begin{array}{r}48, \\
9\end{array}$ & $\begin{array}{r}49, \\
2\end{array}$ & $\begin{array}{r}125 \\
9\end{array}$ & 122 & $\begin{array}{r}34 \\
6\end{array}$ \\
\hline 4 & 45 & 45 & $\begin{array}{c}10 \\
8\end{array}$ & 107 & 45 & 45 & 115 & 100 & $\begin{array}{r}30 \\
5\end{array}$ \\
\hline 5 & 45 & 45 & $\begin{array}{c}10 \\
8\end{array}$ & 107 & 45 & 45 & 115 & 100 & $\begin{array}{r}30 \\
5\end{array}$ \\
\hline 6 & 45 & 45 & $\begin{array}{c}10 \\
8\end{array}$ & 107 & 45 & 45 & 115 & 100 & $\begin{array}{r}30 \\
5\end{array}$ \\
\hline 7 & 85 & 85 & $\begin{array}{c}10 \\
8 \\
\end{array}$ & 107 & $\begin{array}{r}52 \\
4 \\
\end{array}$ & $\begin{array}{r}55 \\
2 \\
\end{array}$ & $\begin{array}{r}131, \\
2 \\
\end{array}$ & $\begin{array}{r}146, \\
2 \\
\end{array}$ & $\begin{array}{r}38 \\
5 \\
\end{array}$ \\
\hline 8 & 85 & 85 & $\begin{array}{c}10 \\
8 \\
\end{array}$ & 107 & $\begin{array}{r}52 \\
4 \\
\end{array}$ & $\begin{array}{r}55 \\
2 \\
\end{array}$ & $\begin{array}{r}131, \\
2 \\
\end{array}$ & $\begin{array}{r}146, \\
2 \\
\end{array}$ & $\begin{array}{r}38 \\
5 \\
\end{array}$ \\
\hline 9 & 45 & 45 & $\begin{array}{c}10 \\
8\end{array}$ & 107 & 45 & 45 & 115 & 100 & $\begin{array}{r}30 \\
5\end{array}$ \\
\hline 10 & 45 & 45 & $\begin{array}{c}10 \\
8\end{array}$ & 107 & 45 & 45 & 115 & 100 & $\begin{array}{r}30 \\
5 \\
\end{array}$ \\
\hline 11 & 45 & 45 & $\begin{array}{c}10 \\
5\end{array}$ & 102 & 45 & 45 & 107 & 100 & $\begin{array}{r}29 \\
7\end{array}$ \\
\hline 12 & 45 & 45 & $\begin{array}{c}17 \\
0\end{array}$ & 175 & $\begin{array}{r}56 \\
8\end{array}$ & 63 & $\begin{array}{r}138, \\
1\end{array}$ & $\begin{array}{r}177, \\
1\end{array}$ & $\begin{array}{r}43 \\
5\end{array}$ \\
\hline 13 & 45 & 45 & $\begin{array}{c}17 \\
0\end{array}$ & 175 & $\begin{array}{r}56 \\
8\end{array}$ & 63 & $\begin{array}{r}138, \\
1\end{array}$ & $\begin{array}{r}177, \\
1\end{array}$ & $\begin{array}{r}43 \\
5\end{array}$ \\
\hline 14 & 45 & 45 & $\begin{array}{c}10 \\
8 \\
\end{array}$ & 90 & 45 & 45 & 108 & 90 & $\begin{array}{r}28 \\
8\end{array}$ \\
\hline 15 & 45 & 45 & $\begin{array}{c}10 \\
8\end{array}$ & 107 & 45 & 45 & 115 & 100 & $\begin{array}{r}30 \\
5\end{array}$ \\
\hline
\end{tabular}




\begin{tabular}{|c|c|c|c|c|c|c|c|c|c|}
\hline 16 & 45 & 45 & $\begin{array}{c}16 \\
0\end{array}$ & 160 & $\begin{array}{r}54, \\
6\end{array}$ & $\begin{array}{r}59, \\
1\end{array}$ & $\begin{array}{r}134 \\
7\end{array}$ & $\begin{array}{r}161, \\
6\end{array}$ & $\begin{array}{r}41 \\
0\end{array}$ \\
\hline 17 & 85 & 85 & $\begin{array}{c}10 \\
8 \\
\end{array}$ & 107 & $\begin{array}{r}52 \\
4 \\
\end{array}$ & $\begin{array}{r}55, \\
2 \\
\end{array}$ & $\begin{array}{r}131, \\
2 \\
\end{array}$ & $\begin{array}{r}146, \\
2 \\
\end{array}$ & $\begin{array}{r}38 \\
5 \\
\end{array}$ \\
\hline 18 & 45 & 45 & $\begin{array}{c}10 \\
8 \\
\end{array}$ & 175 & $\begin{array}{r}51, \\
3\end{array}$ & $\begin{array}{r}53 \\
4\end{array}$ & $\begin{array}{r}129 \\
6\end{array}$ & $\begin{array}{r}138 \\
7\end{array}$ & $\begin{array}{r}37 \\
3\end{array}$ \\
\hline 19 & 45 & 45 & $\begin{array}{c}16 \\
0\end{array}$ & 160 & $\begin{array}{r}54, \\
6 \\
\end{array}$ & $\begin{array}{r}59, \\
1\end{array}$ & $\begin{array}{r}134 \\
7 \\
\end{array}$ & $\begin{array}{r}161, \\
6\end{array}$ & $\begin{array}{r}41 \\
0 \\
\end{array}$ \\
\hline 20 & 45 & 45 & $\begin{array}{c}10 \\
8\end{array}$ & 107 & 45 & 45 & 115 & 100 & $\begin{array}{r}30 \\
5\end{array}$ \\
\hline 21 & 85 & 85 & $\begin{array}{c}10 \\
8\end{array}$ & 107 & $\begin{array}{r}52 \\
4\end{array}$ & $\begin{array}{r}55, \\
2\end{array}$ & $\begin{array}{r}131, \\
2\end{array}$ & $\begin{array}{r}146, \\
2\end{array}$ & $\begin{array}{r}38 \\
5\end{array}$ \\
\hline 22 & 45 & 45 & $\begin{array}{c}10 \\
8 \\
\end{array}$ & 107 & 45 & 45 & 115 & 100 & $\begin{array}{r}30 \\
5 \\
\end{array}$ \\
\hline 23 & 45 & 45 & 0 & 175 & 45 & 45 & $\begin{array}{r}117, \\
2 \\
\end{array}$ & 57,8 & $\begin{array}{r}26 \\
5 \\
\end{array}$ \\
\hline 24 & 45 & 46 & $\begin{array}{c}10 \\
7\end{array}$ & 107 & 45 & 45 & 115 & 100 & $\begin{array}{r}30 \\
5\end{array}$ \\
\hline 25 & 45 & 45 & $\begin{array}{c}10 \\
8\end{array}$ & 107 & 45 & 45 & 115 & 100 & $\begin{array}{r}30 \\
5\end{array}$ \\
\hline 26 & 45 & 45 & $\begin{array}{c}16 \\
0 \\
\end{array}$ & 160 & $\begin{array}{r}54, \\
6 \\
\end{array}$ & $\begin{array}{r}59, \\
1 \\
\end{array}$ & $\begin{array}{r}134 \\
7 \\
\end{array}$ & $\begin{array}{r}161, \\
6 \\
\end{array}$ & $\begin{array}{r}41 \\
0 \\
\end{array}$ \\
\hline 27 & 45 & 46 & $\begin{array}{c}16 \\
9\end{array}$ & 160 & $\begin{array}{r}55, \\
5\end{array}$ & $\begin{array}{r}60, \\
7\end{array}$ & 136 & $\begin{array}{r}167 \\
8\end{array}$ & $\begin{array}{r}42 \\
0\end{array}$ \\
\hline 28 & 45 & 45 & $\begin{array}{c}17 \\
0\end{array}$ & 175 & $\begin{array}{r}56 \\
8 \\
\end{array}$ & 63 & $\begin{array}{r}138 \\
1 \\
\end{array}$ & $\begin{array}{r}177, \\
1 \\
\end{array}$ & $\begin{array}{r}43 \\
5 \\
\end{array}$ \\
\hline 29 & 45 & 45 & 0 & 107 & 45 & 45 & 46,3 & 60,7 & $\begin{array}{r}19 \\
7\end{array}$ \\
\hline 30 & 45 & 45 & 0 & 107 & 45 & 45 & 46,3 & 60,7 & $\begin{array}{r}19 \\
7\end{array}$ \\
\hline 31 & 46 & 85 & 0 & 107 & 45 & 45 & 74,8 & 73,2 & $\begin{array}{r}23 \\
8\end{array}$ \\
\hline
\end{tabular}

2. Pembebanan Periode Gas

Data yang digunakan adalah data pembebanan pada tanggal 1 hingga 31 Juli 2015. Hasil perhitungan pembebanan metode dynamic genetic algorithm dan perbandingan dengan pembebanan PJB ditunjuukan pada tabel 3.

3. Analisis Konsumsi Bahan Bakar Periode Gas

Dari gambar 7, pembebanan yang didapatkan pada perhitungan sebelumnya, dihitung konsumsi bahan bakar yang digunakan pada masing-masing pembangkit. Dari gambar 7, dapat dilihat bahwa PLTU 1, PLTU 2, PLTU 3 konsumsi bahan bakar yang digunakan lebih murah dengan menggunakan metode dynamic genetic algorithm, sementara pada PLTU 4 lebih murah PJB. Akan tetapi, secara keseluruhan, metode dynamic genetic algorithm dapat menghemat 3.162,9147 $\mathrm{KNM}^{3}$ dibandingkan PT. PJB UP Gresik.

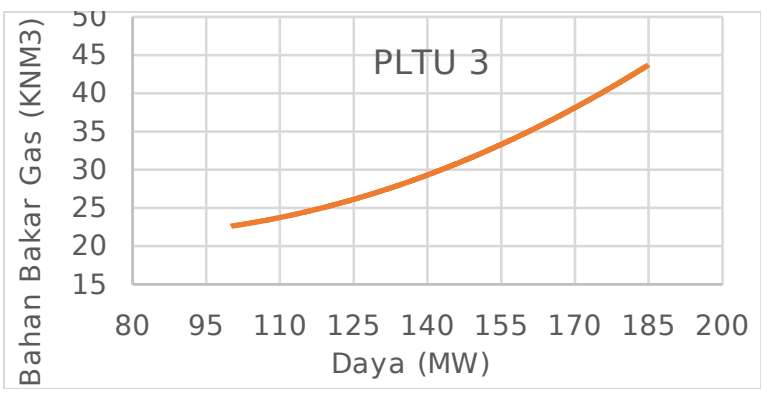

Gambar 5. Kurva Karakteristik Input-Output PLTU 3

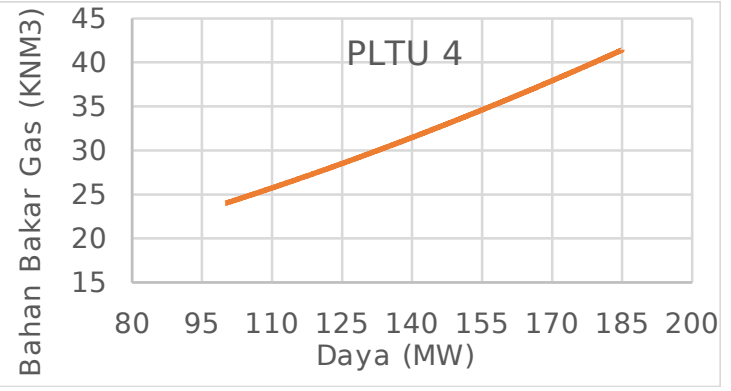

Gambar 6. Kurva Karakteristik Input-Output PLTU 4

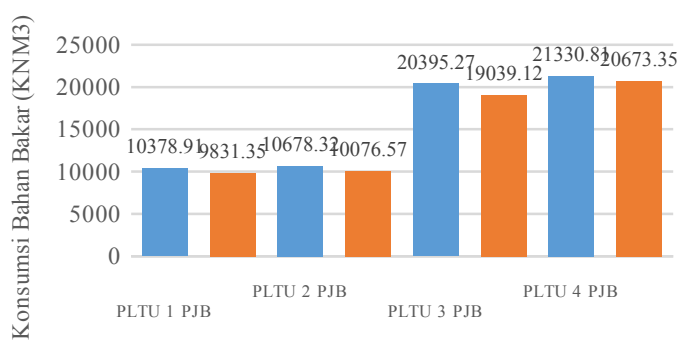

Gambar 7. Perbandingan Konsumsi Bahan Bakar

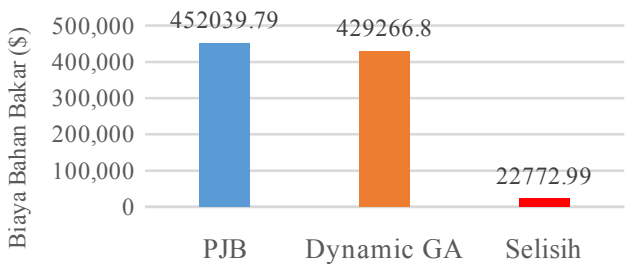

Gambar 8. Perbandingan Biaya Bahan Bakar

4. Analisis Biaya Bahan Bakar Periode Gas

Dari gambar 8 dapat diketahui bahwa biaya bahan bakar menggunakan pembebanan PT. PJB UP Gresik menghabiskan biaya $\$ 452.040$ sedangkan biaya bahan bakar menggunakan pembebanan dynamic genetic algorithm menghabiskan dana \$429.261. Dengan ini dapat diambil kesimpulan bahwa, pembebanan menggunakan metode dynamic genetic algorithm memiliki biaya lebih murah dengan penghematan sebesar \$22.773.

\section{KESIMPULAN}

1. Karakteristik input-output periode gas masih baik, sementara pada periode liquid, PLTU 1 masih memiliki performa yang baik, sedangkan PLTU 2 telah mengalami pergeseran.

2. Pada periode gas, konusmsi bahan bakar dihemat $3.162,9147 \mathrm{KNM}^{3}$ dan biaya bahan bakar dihemat $\$ 22.773$ dibandingkan PJB, sedangkan pada periode liquid, konsumsi bahan bakar dapat dihemat 16.532,2189 liter dan biaya bahan bakar dihemat Rp. 1.131.369.852 dibandingkan PJB 
3. Perbandingan metode dynamic genetic algorithm dengan metode PSO dari segi pembebanan, maka metode dynamic genetic algorithm dapat membagi beban sesuai acuan, sementara PSO memiliki selisih -1 hingga 42 MW. Dynamic genetic algorithm memiliki konsumsi bahan bakar 245,24 liter dan biaya bahan bakar Rp. 1.477 .569 lebih hemat dibanding metode PSO.

4. Perbandingan metode dynamic genetic algorithm dengan metode SA dari segi pembebanan, maka metode dynamic genetic algorithm dapat membagi beban sesuai acuan, sementara SA memiliki selisih -0,0001 hingga 0,0001 MW. Dynamic genetic algorithm memiliki konsumsi bahan bakar 50.511,12 liter dan biaya bahan bakar Rp. 304.329.523 lebih hemat dibanding metode SA.

\section{DAFTAR PUSTAKA}

[1] Basuki, Cahyo Adi, Ir. Agung Nugroho \& Ir. Bambang Winardi. 2011. Analisis Konsumsi Bahan Bakar Pada Pembangkit Listrik Tenaga Uap Dengan Menggunakan Metode Least Square. Semarang : Universitas Diponegoro.

[2] Tzung-Pei Hong. 2002. Evolution of Appropriate Crossover and Mutation Operators in a Genetic Process. Journal of Departmen Information Management I-Shou Universitty \& Institute of Electrical Engineering Chung-Hua University. 